\title{
TRANSIENT LIQUID PHASE BONDING OF NEWLY DEVELOPED HAYNES 282 SUPERALLOY
}

\author{
A. Ghoneim and O. A. Ojo \\ Department of Mechanical and Manufacturing Engineering \\ University of Manitoba \\ Winnipeg, Manitoba, Canada, R3T 5V6
}

Keywords: Transient Liquid Phase Bonding, Diffusion Brazing, Superalloy, Haynes 282

\begin{abstract}
Transient Liquid Phase Bonding (TLP) of Haynes 282 was performed to study the influence of process parameters on TLP joint microstructure in the newly developed superalloy. Insufficient holding time for complete isothermal solidification of liquated insert caused formation of eutectic-type microconstituent along the joint centerline region. In contrast to general expectation, an increase in bonding temperature above a certain temperature resulted in a decrease in isothermal solidification rate and formation of the centreline eutectic that was avoided with same holding time at a lower temperature. Application of finite element numerical simulation showed that the anomalous behaviour can be explained by deviation from parabolic relationship between solid/liquid interface migration and holding time induced by reduction in solute concentration gradient in the solid substrate below a critical value. Comparison of the present experimental results in Haynes 282 with those in other nickel based superalloys, like IN 738 , shows that the undesirable reduction in isothermal solidification rate is significantly less pronounced in the Haynes 282. This is attributable to a more extensive formation of interface Mo-rich borides in the new alloy, which can relieve boron saturation in the matrix phase and, thus, lessens the occurrence of the deviation phenomenon.
\end{abstract}

\section{Introduction}

Continual demand for higher efficiency in aero-engines has necessitated the development of better heat resistant materials, such as, $\gamma^{\prime}$ precipitation strengthened nickel-based superalloys for the manufacturing of hot section components used in gas turbines. A new $\gamma^{\prime}$ precipitation strengthened nickel based superalloy, Haynes 282, has been developed to enable higher performance of aircraft and land-based gas turbine engines [1]. The alloy exhibits a unique combination of excellent creep properties, fabricability and thermal stability that surpass that of Waspaloy. Joining is an essential part of manufacturing processes for producing of heat resistant turbine components. Moreover, higher engine efficiency involves increased stresses at higher operating temperatures, which can result in accelerated creep, fatigue and oxidation degradation of superalloy components. The high cost of superalloy components and the long processing time for the manufacture of new components often make repair of service-damaged components necessary. The most commonly used joining and repair process, welding, is often found unsuitable for precipitation hardened nickel-based superalloys due to their high susceptibility to hot cracking during welding and post weld heat treatment cracking [2,3]. 
Combining the merits of diffusion bonding and liquid phase joining processes, transient liquid phase (TLP) bonding is an attractive alternative for joining and repair of nickel-based superalloy components [4]. TLP bonding involves sandwiching a filler material containing a melting point depressant element between the substrate layers, and subjecting the assembly to a high temperature, usually between the liquidus temperature of the filler and the solidus temperature of the base-alloy. The key benefit of the TLP bonding relies on the fact that through proper process optimization it is possible to prevent the formation of deleterious eutectic microconstituent that degrades properties of materials joined by conventional brazing technique. The effect of TLP bonding parameters in preventing the eutectic formation, however, can be highly influenced by the chemical composition of the base material in a way that may not be predicted intuitively.

The objective of the present work was to study the influence of TLP bonding parameters on joint microstructure in the newly developed Haynes 282, with the use of a commercial filler alloy, and the results are reported and discussed in this paper.

\section{Experimental Procedure}

The base material used in this work was wrought Haynes 282 superalloy with chemical composition of (wt \%) 0.06C, 20Cr, 10Co, 8.5Mo, 1.5Fe, 1.5 Al, 2.1Ti, 0.3Mn, 0.15 Si, 0.005B balance nickel and the filler alloy was Metglass MBF 80 with composition of (wt\%) 15Cr, 4B, $0.06 \mathrm{C}$ maximum and balance $\mathrm{Ni}$. Test specimens in the form of $6 \times 6 \times 12 \mathrm{~mm}$ coupons were machined from as-received with the use of a numerically controlled wire electro-discharge machine (EDM). Prior to TLP bonding, the contacting surfaces were polished to remove re-cast surface layer and to produce smooth faying surfaces. The filler alloy was sandwiched between the mating surfaces and a stop-off material was applied on the periphery of the joint assembly to prevent spillage of liquated insert alloy during bonding. Bonding was carried out in a vacuum furnace at an operating vacuum of $10^{-4}-10^{-5}$ Torr at $1200^{\circ} \mathrm{C}$. Bonded specimens were sectioned by the EDM and the sectioned pieces were subsequently subjected to standard metallographic sample preparation for microstructural study by optical and scanning electron microscopy (SEM). Cross sections of the TLP joints were etched using Kallings etchant containing $48 \mathrm{~g}$ of $\mathrm{CuCl}_{2}, 480 \mathrm{ml}$ of $\mathrm{HCl}$ and $40 \mathrm{ml}$ of distilled water. Preliminary metallographic assessment of the joint microstructure was performed by an inverted-reflected light microscope equipped with a CLEMEX Vision 3.0 image analyzer. A minimum of twenty measurements was taken to calculate the average centerline eutectic width in all the specimens. Further microstructural study was performed on a JEOL 5900 scanning electron microscope (SEM) equipped with an ultra-thin window Oxford energy dispersive spectrometer. Numerical simulation of the TLP bonding process was performed by developing a 2-D transient fully implicit algorithm using the finite element method to solve the classical Fick's diffusion equation and to track the location of the moving liquid-solid interface with respect to time.

\section{Results and Discussion}

\section{Effect of Holding Time on Joint Microstructure}

In order to study the effect of holding time on the TLP joint microstructure, $80 \mu \mathrm{m}$ gap samples were bonded at $1100^{\circ} \mathrm{C}$ for 30 and 60 minutes. The microstructure of the samples is shown in Figures 1 (a-c). As shown in Figures 1a, the microstructure of the joint prepared for 30 minutes consists of a continuous eutectic product along the centreline region. A 60 minutes holding at the temperature produced a joint completely free of the centreline eutectic as shown in Figure 1c. Semi-quantitative SEM chemical compositional analysis of the three main phases within the 
eutectic by electron dispersive spectroscopy EDS (Table 1) and comparison with published data [5] suggest that the phases are based on nickel-rich boride, chromium-rich boride, and nickelbased solid solution phase. Boron was detected in the boron rich particle but could not be quantified due to the inability of the EDS software to quantify the light element accurately. During TLP bonding, diffusion of melting point depressant (MPD) solute from the interlayer liquid into the solid substrate causes isothermal solidification of the liquid to proceed inward from the solid-liquid surfaces toward the joint centerline. The centerline eutectic microconstituent observed in the present work is believed to be formed by non-equilibrium solidification of residual interlayer liquid during cooling, due to an insufficient diffusion time to induce complete isothermal solidification. Formation of the centerline eutectic in a continuously distributed fashion could be deleterious to mechanical properties, as it may provide a low resistance path for crack initiation and/or propagation as reported in some alloys [6, 7]. Therefore, to prevent the formation of the eutectic, it is necessary to use adequate holding time during bonding to achieve complete isothermal solidification of the liquid.

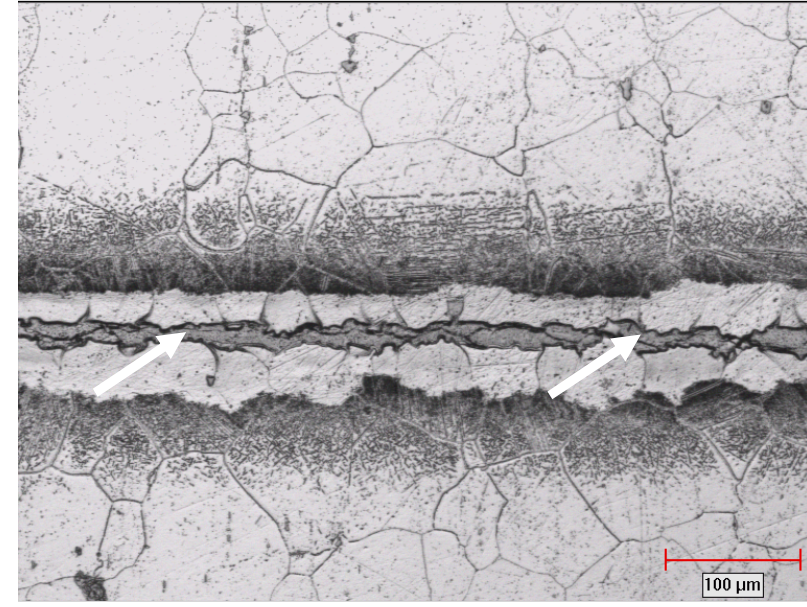

Figure 1a: Optical micrograph of joint prepared at $1100^{\circ} \mathrm{C}$ for 30 mins containing centreline eutectic.

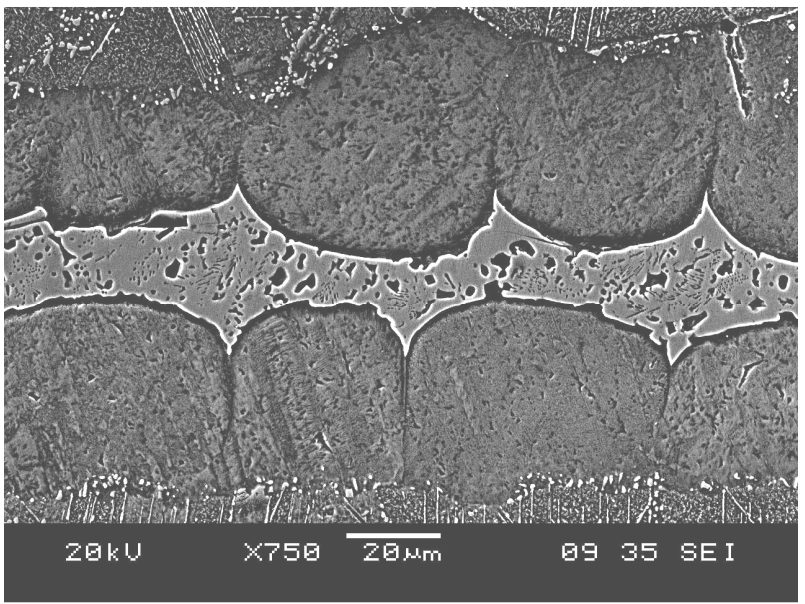

Figure 1b: SEM micrograph of the joint prepared at $1100^{\circ} \mathrm{C}$ for $1 \mathrm{hr}$ showing the centreline eutectic at a higher magnification.

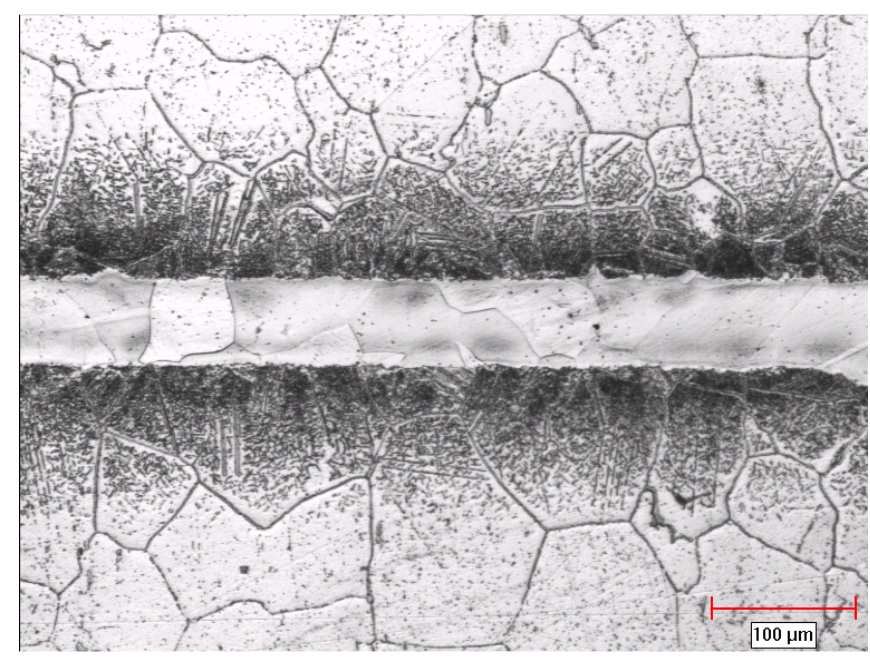

Figure 1c. Optical micrograph of specimens bonded at $1100^{\circ} \mathrm{C}$ for 60 mins showing eutectic-free joint. 
Table 1: SEM-EDS Semi-Quantitative Analysis of Phases Present within the TLP Joint Centreline Eutectic (wt \%)

\begin{tabular}{|c|c|c|c|c|c|c|c|}
\hline Phase & $\mathrm{Cr}$ & $\mathrm{Co}$ & $\mathrm{Ti}$ & $\mathrm{Al}$ & $\mathrm{Fe}$ & $\mathrm{Mo}$ & $\mathrm{Ni}$ \\
\hline $\begin{array}{c}\text { Ni-based } \\
\text { solid solution }\end{array}$ & 17.1 & 1.4 & 0.2 & 0.3 & 0.3 & 0.6 & 80 \\
\hline Cr-rich boride & 65.2 & 1.1 & - & - & 0.2 & 10.5 & 23.0 \\
\hline Ni-rich boride & 11.6 & 1.3 & 1.3 & - & 0.2 & 0.5 & 85 \\
\hline
\end{tabular}

\section{Effect of Bonding Temperature on Joint Microstructure}

In order to study the effect of bonding temperature on joint microstructure, $80 \mu \mathrm{m}$ gap sized samples were bonded at $1130^{\circ} \mathrm{C}, 1180^{\circ} \mathrm{C}$ and $1200^{\circ} \mathrm{C}$ for $1 \mathrm{hr}$. The microstructure of joints prepared at all the temperatures are presented in Figures $2(\mathrm{a}-\mathrm{c})$. Similar to the case at $1100^{\circ} \mathrm{C}$, a $1 \mathrm{hr}$ holding time was sufficient to achieve complete isothermal solidification of the interlayer liquid at $1130^{\circ} \mathrm{C}$, which resulted in a eutectic-free joint as shown in Figure 2a. Conversely, however, by increasing the bonding temperature to $1180^{\circ} \mathrm{C}$ and above, the isothermal solidification rate reduced, such that, the $1 \mathrm{hr}$ holding time was inadequate to completely solidify the liquid isothermally. Accordingly, the joints produced at $1180^{\circ} \mathrm{C}$ and $1200^{\circ} \mathrm{C}$ for $1 \mathrm{hr}$ contain continuous centreline eutectic, which was prevented at lower temperatures $1100^{\circ} \mathrm{C}$ and $1130^{\circ} \mathrm{C}$. The average width of the eutectic increased from $15 \mu \mathrm{m}$ to $35 \mu \mathrm{m}$ with an increase in temperature from $1180^{\circ} \mathrm{C}$ to $1200^{\circ} \mathrm{C}$.


Figure 2: (a) Micrograph of eutectic-free joint prepared at $1130^{\circ} \mathrm{C}$ for 60 mins. (b) Optical micrograph of joint prepared at $1180^{\circ} \mathrm{C}$ for 60 mins containing centreline eutectic. (c) Optical micrograph of joint prepared at $1200^{\circ} \mathrm{C}$ for 60 mins containing centreline eutectic. 
A number of analytical models have been developed to estimate the time, $t_{\mathrm{f}}$, that is required to achieve complete isothermal solidification of interlayer liquid during TLP bonding [8-11]. Generally, in these models, the time $t_{\mathrm{f}}$ can be approximated by:

$$
t_{f}^{1 / 2}=\frac{2 h}{\gamma 4 D^{1 / 2}}
$$

where, $\mathrm{D}$ is diffusion coefficient of the melting point depressant in the solid base alloy, and $2 \mathrm{~h}$ is the maximum width of the braze insert following its equilibration at solid-liquid interface. $\gamma$ is a dimensionless parameter, which is estimated by solving the following equation numerically:

$$
\frac{C_{\alpha}-C_{m}}{C_{\beta}-C_{\alpha}}=\gamma \sqrt{\pi} \exp \left(\gamma^{1 / 2}(1+e r f \gamma)\right)
$$

where, $\mathrm{C}_{\alpha}$ and $\mathrm{C}_{\beta}$ are solute concentration in the solid and liquid phase at the migrating interface, respectively, and $\mathrm{C}_{\mathrm{m}}$ is the initial solute concentration in the base alloy.. According to these models, and equation 1, isothermal solidification stage is considered to be complete when the concentration of the melting point depressant solute at center of the liquated interlayer is reduced to the value of the concentration of the melting point depressant solute at the solvus, $\mathrm{C}_{\mathrm{s}}$. An increase in bonding temperature is expected to significantly increase isothermal solidification rate and reduce $t_{\mathrm{f}}$. The observation of reduction in isothermal solidification rate with an increase in temperature to $1180^{\circ} \mathrm{C}$, made in the present work, is in contrast to the expectation of increased solidification rate.

A general assumption during analytical modeling of TLP bonding that during isothermal solidification stage, is that diffusion-induced migration of the solid/liquid interface, $\mathrm{m}$, follows a parabolic law,

$$
\mathrm{m}=2 \varphi\left(\mathrm{t}^{1 / 2}\right)
$$

where $\mathrm{t}$ is the holding time and the parameter $\varphi$ indicates the rate of interface migration. This indicates a linear relationship between residual liquid thickness and square root of holding time. Despite reduction in the concentration gradient of MPD solute in the base material due to its continual diffusion during bonding, it is assumed in these models that the solid/liquid interface displacement maintains its parabolic behavior with time throughout the entire isothermal solidification process. In practice, however, this may constitute a largely inaccurate assumption that could lead to consequential deviation of experimental observation from prediction based on the standard analytical models. This can be duly investigated by using computation numerical analysis to solve the original Fick's diffusion equation. In the present work a 2-D transient fully implicit algorithm was developed using finite element method to solve the classical Fick's diffusion equation, which can be expressed in a partial differential equation:

$$
\frac{\partial C_{j}}{\partial t}=D_{j} \cdot \nabla^{2} C_{j}
$$


Where $C_{j}$ is the composition of the liquid and solid phases, $D_{j}$ is the interdiffusion coefficient, $j=$ $\mathrm{s}$ for the solid phase and $\mathrm{j}=1$ for the liquid phase. The numerical computational analysis was used to simulate the isothermal solidification process of TLP bonding. The simulation was performed for TLP bonding of nickel containing an initial boron concentration of $0 \mathrm{wt}$ \% with a filler alloy containing 3.6 wt.\% of boron. Figures $3 \mathrm{a}$ and $3 \mathrm{~b}$ show plots of residual liquid halflayer thickness against square root of holding time and the corresponding distribution of boron concentration in the base metal after completion of isothermal solidification, respectively, for different gap sizes. As can be seen by the plots, a linear relationship exists between interlayer liquid and square root of holding time during the time, $t_{f}$, required to achieve complete isothermal solidification for gap sizes of 80 and $100 \mu \mathrm{m}$. An increase in the gap size to 130 and $150 \mu \mathrm{m}$, however, resulted in a considerable deviation from the linear relationship toward the end of isothermal solidification, which can be related to the concomitant reduction in solutes concentration gradient below a certain critical level, $(\partial \mathrm{C} / \partial \mathrm{x})_{\mathrm{c}}$. This indicates that an increase in diffusion of MPD solute can lead to a situation where the parabolic relationship between solid/liquid interface displacement and holding time would cease to hold due to a considerable reduction in solute concentration gradient. A review of the reported data in the literature showed deviation from the parabolic rule under some experimental conditions [12-14].

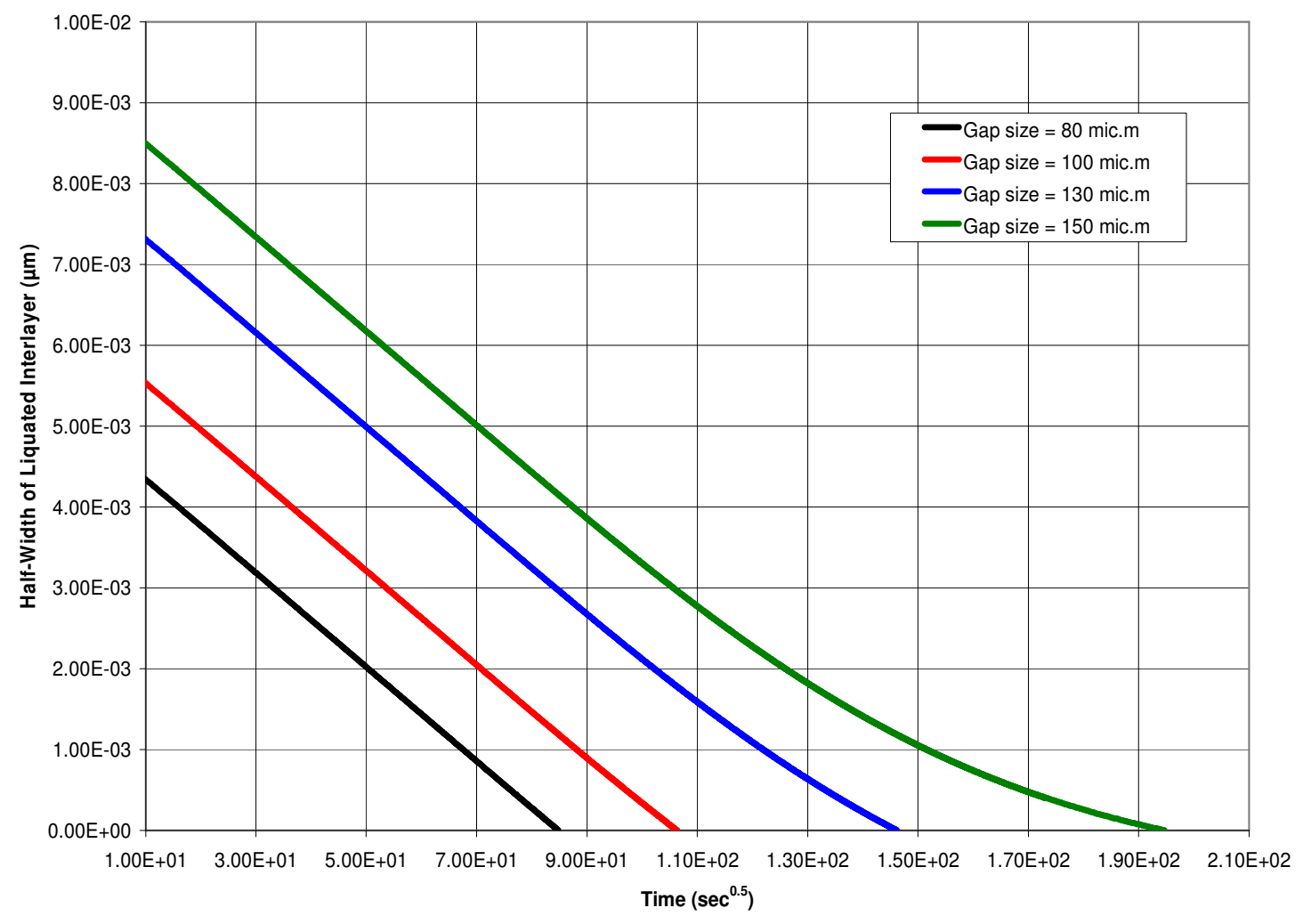

Figure 3a Numerical simulation plots of half-width of liquid interlayer against holding time for different gap sizes 


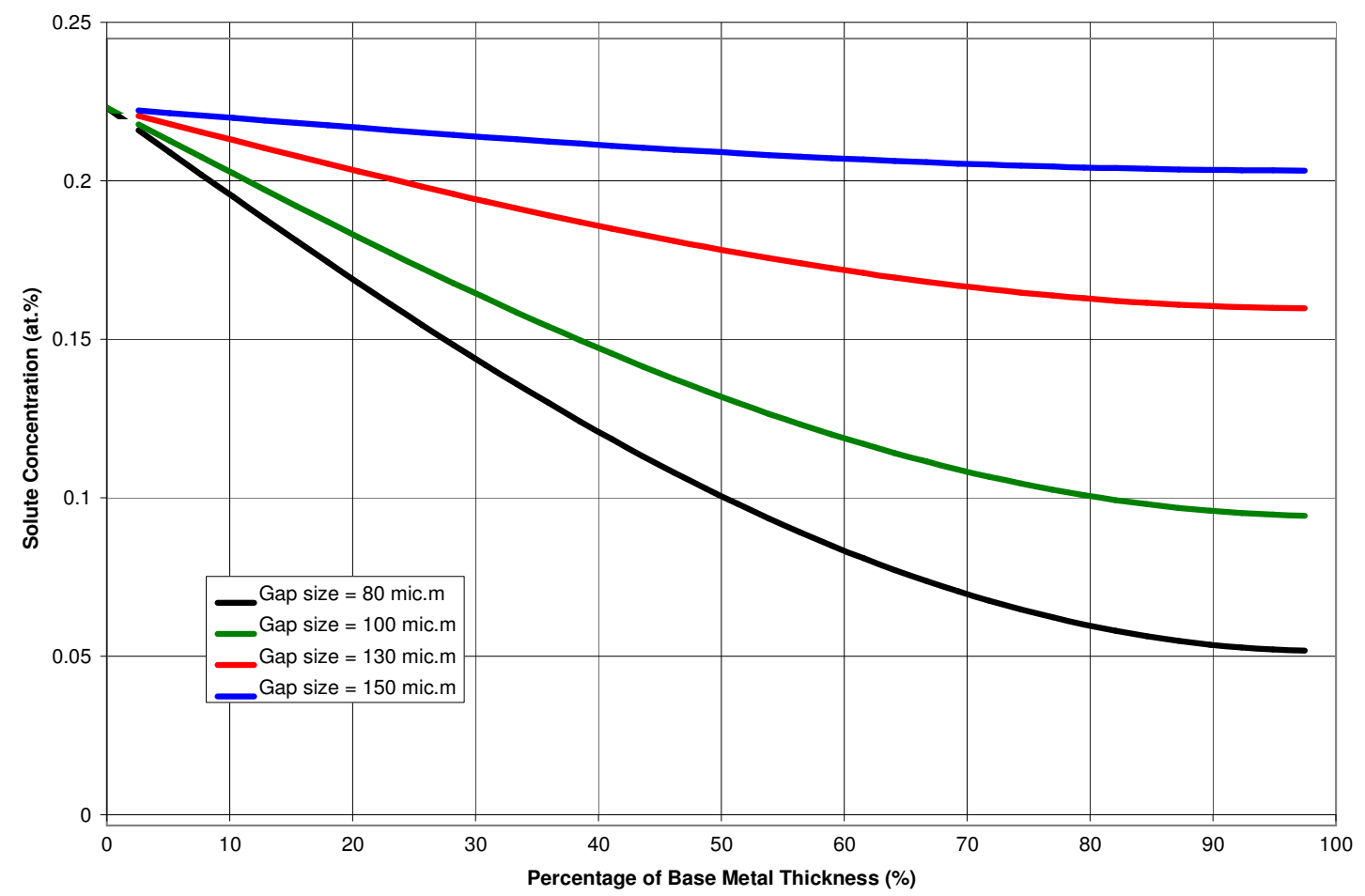

Figure $3 \mathrm{~b}$ Solute concentration profile in the base material for different gap sizes.

An important possible consequence of this deviation from parabolic behavior, with regard to a crucial joining parameter, bonding temperature, is vital. At the onset of deviation, the rate of isothermal solidification starts to decrease and the constant parameter $\varphi$ in equation (2) becomes inadequate in representing the rate. The rate of decrease of isothermal solidification within the deviation zone and, as a result, the time required for complete isothermal solidification, are dependent on the magnitude of $(\partial \mathrm{C} / \partial \mathrm{x})$ within the region. The $(\partial \mathrm{C} / \partial \mathrm{x})$ is influenced by the solubility of diffusing solute at any particular bonding temperature, with a decrease in solubility causing a decrease in $(\partial \mathrm{C} / \partial \mathrm{x})$. Above any temperature where deviation from parabolic behavior occurs, reduction in $(\partial \mathrm{C} / \partial \mathrm{x})$ due to a decrease in solute solubility with an increase in temperature (as it exits above Ni-B eutectic temperature) will produce extended deviation zone with augmented isothermal solidification rate reduction. This could lead to a situation where a longer holding time, $\mathrm{t}_{\mathrm{f}}$, will be required to produce eutectic-free joint through complete isothermal solidification at a higher bonding temperature compared to what is needed at a lower temperature. This was observed in the present work, as stated earlier, while a $1 \mathrm{hr}$ holding time produced a eutectic-free joint at $1100{ }^{\circ} \mathrm{C}$ and $1130^{\circ} \mathrm{C}$, the same holding time was found inadequate to prevent the eutectic formation at higher temperatures $1180{ }^{\circ} \mathrm{C}$ and $1200^{\circ} \mathrm{C}$. Similar observation has been also reported in other nickel based superalloys, such as, IN 738 and Waspaloy [15]. However, in comparison to these other superalloys, the extent of increase in $t_{f}$ at higher temperatures is considerably smaller in the new alloy Haynes 282. A holding time of $3 \mathrm{hrs}$ resulted in complete isothermal solidification and eutectic-free joint in an $80 \mu \mathrm{m}$ joint produced at $1180^{\circ} \mathrm{C}$ in Haynes 282 (Figure $4 \mathrm{a}$ ). At the same bonding temperature and same gap size, an 8 hrs of holding time was insufficient to isothermally solidify the interlayer liquid in IN 738, which resulted in a joint that contains the centerline eutectic (Figure 4b). 

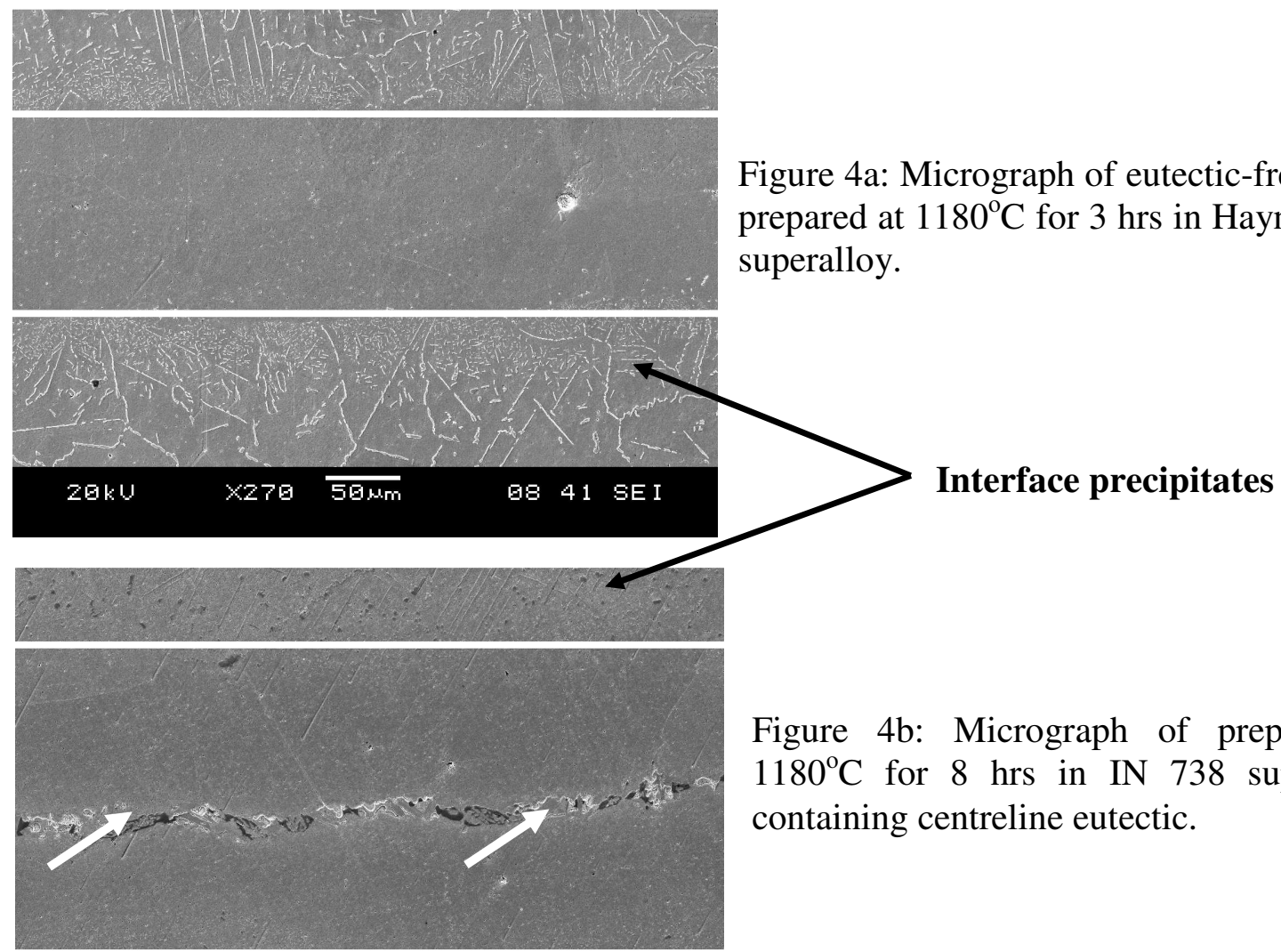

Figure 4b: Micrograph of prepared at $1180^{\circ} \mathrm{C}$ for $8 \mathrm{hrs}$ in IN 738 superalloy containing centreline eutectic.

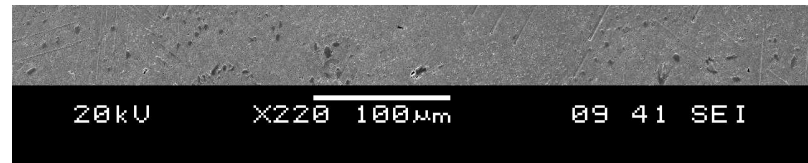

Interestingly, while diffusion coefficient does increase with temperature, an increase in solute diffusion coefficient basically has no effect on deviation from parabolic behavior as shown in simulation results in Figure 5a. Increasing solute diffusion coefficient only reduces the time at which deviation starts but it is ineffective in preventing its occurrence. Conversely, however, based on the concept of deviation from parabolic law, an increase in solubility of the MPD in the base material would increase $\partial \mathrm{C} / \partial \mathrm{x}$, which in effect can reduce or eliminate the occurrence of deviation (Figure 5b). This implies that an increase in the capability of the base material in accommodating the MPD solute and, thus, lessen reduction in $\partial \mathrm{C} / \partial \mathrm{x}$ can alleviate the occurrence of the deviation. Solute accommodation capability of the base-alloy can be enhanced by depletion of substrate matrix solute content through the formation of solute-rich second phase precipitates. Second phase precipitates rich in Mo and B were observed within the base-alloy region adjacent to the joint interface in all the bonded Haynes 282 specimens. Molybdenum is known to have a high affinity for boron and several Mo-rich borides, such as $M_{3} B_{2}$ and $M_{5} B_{3}$ form in nickel-based superalloys [16]. 




Figure 5a: Numerical simulation plots of the effect of solute diffusivity on deviation from parabolic relationship.

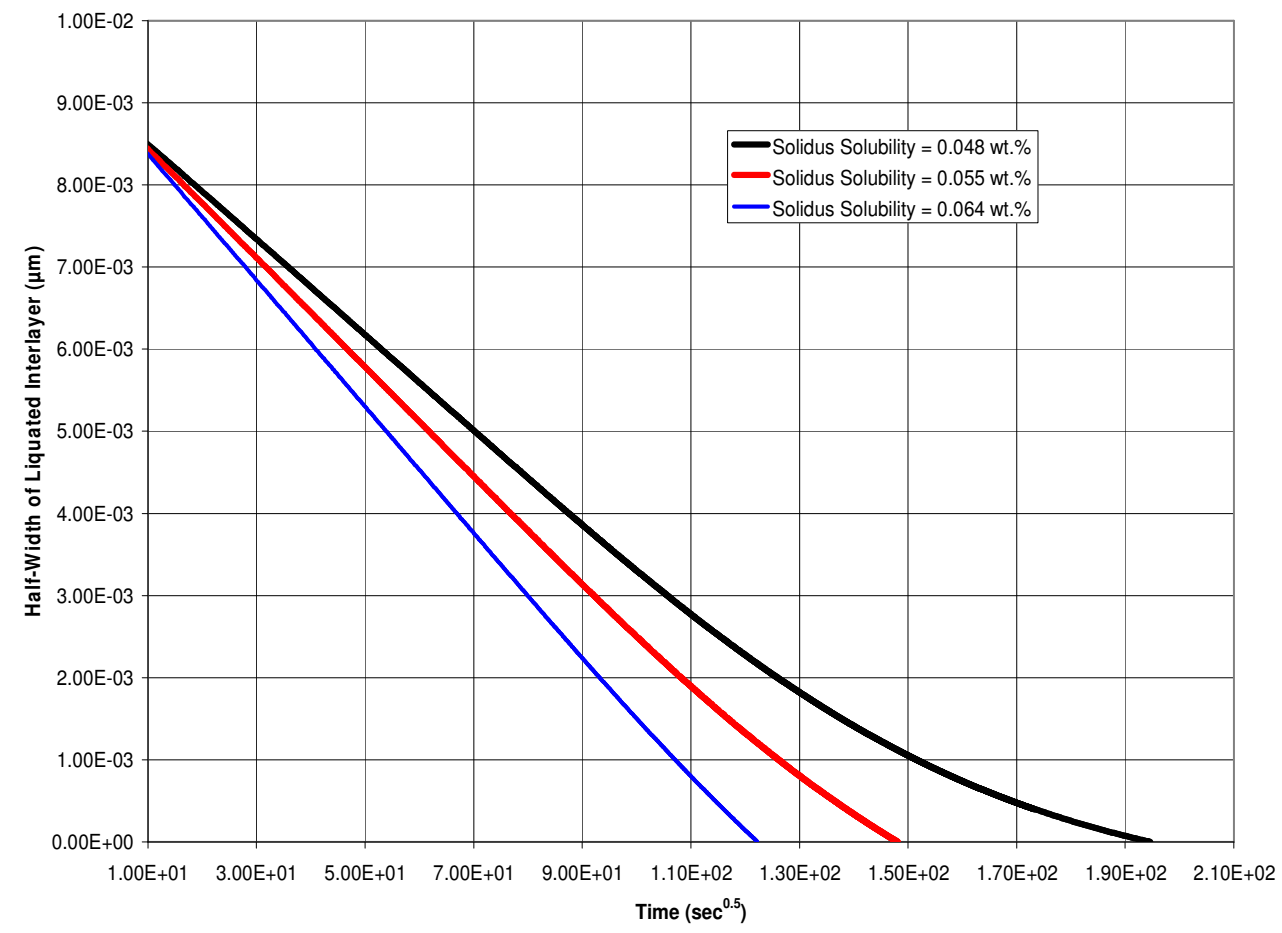

Figure 5b: Numerical simulation plots of the effect of solute solubility on deviation from parabolic relationship. 

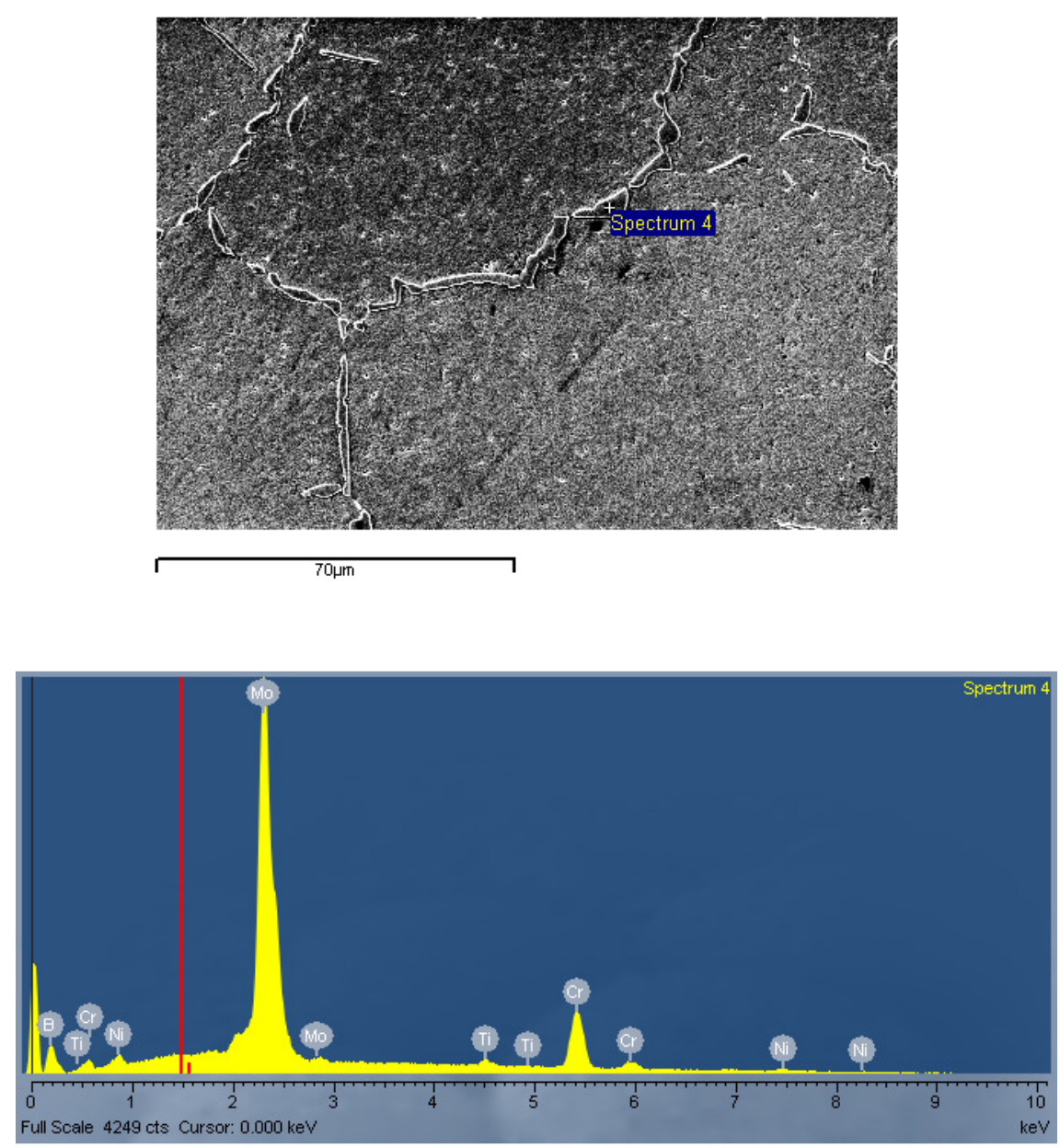

Figure 6a: SEM-EDS spectral from an interface boride particle in Haynes 282.

A careful microstructural study showed that a larger extent of interface borides were formed in Haynes 282 compared to IN 738 joints prepared at $1180^{\circ} \mathrm{C}$ (Figures $4 \mathrm{a} \& 4 \mathrm{~b}$ ). This could be related to a considerably higher Mo concentration in Haynes 282, $8 \mathrm{wt} \%$ compared to $1.8 \mathrm{wt} \%$ in IN 738. The extensive formation of interface Mo-rich borides, which could relieve boron saturation of the matrix phase, may be responsible for the curtailment of time $t_{f}$ elongation at higher temperatures during TLP bonding of the newly developed Haynes 282 superalloy.

\section{Summary and Conclusions}

1. The extent of isothermal solidification of liquated interlayer increased with holding time during TLP bonding of Haynes 282. Incomplete isothermal solidification of the interlayer liquid resulted in formation of centerline eutectic-type microconstituent along the joint. 
2. A significant departure from conventional expectation that an increase in bonding temperature would result in a higher isothermal solidification rate was observed by increasing bonding temperature to $1180^{\circ} \mathrm{C}$ and $1200^{\circ} \mathrm{C}$. Formation of centreline eutectic, which was prevented at lower temperatures $1100^{\circ} \mathrm{C}$ and $1130^{\circ} \mathrm{C}$, occurred in joints prepared at the higher bonding temperatures.

3. In contrast to analytical TLP bonding models, numerical simulation of the process by finite element analysis indicates that deviation from parabolic relationship between solid-liquid interface displacement and holding time can occur during bonding and can explain the anomalous increase in isothermal solidification completion time at higher temperatures.

4. Whilst increasing solute diffusivity basically has no effect of the deviation, an increased solute accommodation capability of the base material can significantly reduce or eliminate the deviation occurrence.

5. Comparison of the results of TLP bonding of Haynes 282 with those of other nickel-based superalloys, like IN 738, with lower Mo concentrations, showed that the prohibitive elongation of time $t_{\mathrm{f}}$ at higher temperatures is less pronounced in Haynes 282. This could be related to enhanced capability of the alloy 282 in accommodating boron atoms through the formation of interface Mo-rich borides.

\section{Acknowledgements}

Contribution of R. Johnston and D. Nuessler to the experimental work of this research, material supply by Haynes International Inc. and financial support from the NSERC of Canada are gratefully acknowledged.

\section{References}

1. L. M. Pike, ASME Turbo Expo 2006, Barcelona, Spain, Paper No. GT-2006-91204.

2. S.D. Duvall and W.A. Owczarski, Weld. J., Vol. 46, No. 9, p. 423s - 432s, (1967).

3. M. B. Henderson, D. Arrell, M. Larsson, G. Marchant, Sci. Technol. Weld. Joining Vol 9. (2004) 13.

4. D. S. Duvall, W. A. Owczarski and D. F. Paulonis, Welding Journal, 9, 46, 1974, pp 203214.

5. O. A. Idowu, O. A. Ojo, and M. C. Chaturvedi, Metallurgical and Materials Transactions A, Vol. 37, pp 2787-2796, 2006.

6. E. Lugscheider, H. Schmoor and U. Eritt,Brazing, high temperature brazing and diffusion welding, 259-261; 1995, Germany, Deutscher Verlag fur Schweisstecknik GMbH.

7. C. Y. Su, C. P. Chou, W. J. Chang and M. H. Liu, J. Mater. Sci. Perform. 2000, 9, 663-668.

8. Y. Nakao, K. Nishimoto, K. Shinozaki and C.Y. Kang, Trans. Jpn. Weld. Soc., Vol. 20, No. 1, p. 60-65, (1989). 
9. W.D. MacDonald and T.W. Eagar, Metall. Trans. A., Vol. 29A, p. 315 - 326, (1998).

10. I. Tuah-Poku, M. Dollar and T.B. Massalski, Metall. Trans. A., Vol. 19A, 675 - 686, (1988).

11. Y. Zhou, W.F. Gale and T.H. North, Int. Mater. Rev., Vol. 40, No. 5, 181-196, (1995).

12. M. L. Kuntz, Ph.D. Dissertation, University of Waterloo (2006).

13. A. Sakamoto, C. Fujiwara, T. Hattori and S. Sakai, Weld. J., 68 (1989) 63.

14. J. E. Ramirez and S. Liu, Weld. J. 71 (1992) 365s.

15. N. Wikstrom, O. A. Idowu, O.A. Ojo, and M.C Chaturvedi, $3^{\text {rd }}$ International Brazing and Soldering Conference, San Antonio, Texas USA, April 23-26, 2006, pp 6-11. K.

16. S. M. Seo, I. S. Kim, J. H. Lee, C. Y. Jo, H. Miyahara and K. Ogi, Metall. and Mater. Trans. A., vol. 38A, p. 883, 2007. 